\title{
Excitotoxic Calcium Overload in a Subpopulation of Mitochondria Triggers Delayed Death in Hippocampal Neurons
}

\author{
Natalia B. Pivovarova, ${ }^{1}$ Huy V. Nguyen, ${ }^{1}$ Christine A. Winters, ${ }^{1}$ Christine A. Brantner, ${ }^{1}$ Carolyn L. Smith,${ }^{2}$ and \\ S. Brian Andrews ${ }^{1}$ \\ ${ }^{1}$ Laboratory of Neurobiology and ${ }^{2}$ Light Imaging Facility, National Institute of Neurological Disorders and Stroke, National Institutes of Health, Bethesda, \\ Maryland 20892-4062
}

In neurons, excitotoxic stimulation induces mitochondrial calcium overload and the release of pro-apoptotic proteins, which triggers delayed cell death. The precise mechanisms of apoptogen release, however, remain controversial. To characterize the linkage between mitochondrial calcium load and cell vulnerability, and to test the hypothesis that only a subpopulation of mitochondria damaged by calcium overload releases apoptogens, we have measured directly the concentrations of total $\mathrm{Ca}$ (free plus bound) in individual mitochondria and monitored in parallel structural changes and the subcellular localization of pro-apoptotic cytochrome $c$ after NMDA overstimulation in cultured hippocampal neurons. Beyond transient elevation of cytosolic calcium and perturbation of $\mathrm{Na}^{+} / \mathrm{K}^{+}$homeostasis, NMDA stimulation induced dramatic, but mainly reversible, changes in mitochondria, including strong calcium elevation, membrane potential depolarization, and variable swelling. Elevation of matrix $\mathrm{Ca}$ in the approximately one-third of mitochondria that were strongly swollen, as well as the absence of swelling when $\mathrm{Ca}^{2+}$ entry was abolished, indicate an essential role for Ca overload. Shortly after NMDA exposure, cytochrome $c$, normally localized to mitochondria, became diffusely distributed in the cytoplasm, coincident with the appearance of severely swollen mitochondria with ruptured outer membranes; under these conditions, cytochrome $c$ was retained in intact mitochondria, implying that it was released mainly from damaged mitochondria. Consistent with the role of mitochondrial Ca overload, carbonyl cyanide p-(trifluoromethoxy)phenylhydrazone decreased Ca accumulation, prevented cytochrome $c$ release, and was neuroprotective. These results support a mechanism in which delayed excitotoxic death involves apoptogen release from a subpopulation of calcium-overloaded mitochondria, whereas other, undamaged mitochondria maintain normal function.

Key words: excitotoxicity; NMDA; mitochondria; calcium; apoptosis; hippocampus; cytochrome $c$

\section{Introduction}

Mitochondrial calcium overload plays a key role in excitotoxic neuronal injury (for review, see Murphy et al., 1999; Reynolds, 1999; Duchen, 2000; Nicholls and Budd, 2000; Gillessen et al., 2002). Evidence for mitochondrial $\mathrm{Ca}^{2+}$ accumulation after excitotoxic stimulation comes from the effects of mitochondrial inhibitors on free cytosolic $\mathrm{Ca}^{2+}$ (White and Reynolds, 1995; Wang and Thayer, 1996), from changes in mitochondria membrane potential $\left(\Delta \Psi_{\mathrm{m}}\right)$ (Khodorov et al., 1996; Schinder et al., 1996; Vergun et al., 1999) and from elevation of free mitochondrial $\mathrm{Ca}^{2+}$ (Peng et al., 1998). The crucial role of mitochondrial $\mathrm{Ca}^{2+}$ accumulation in delayed excitotoxic cell death is indicated by the fact that respiratory uncoupler-induced depolarization of $\Delta \Psi_{\mathrm{m}}$ during glutamate exposure is neuroprotective (Budd and Nicholls, 1996; Stout et al., 1998). Regarding mechanisms of cell

\footnotetext{
Received Feb. 15, 2004; revised May 11, 2004; accepted May 14, 2004.

This work was supported by the National Institutes of Heath Intramural Research Program. We are indebted to staff of the National Institute of Neurological Disorders and Stroke electron microscopy facility and Dr. Jung-Hwa Tao-Cheng, Director, for excellent technical assistance.

Correspondence should be addressed to Dr. Brian Andrews, National Institutes of Health, 36/2A-21, 36 Convent Drive, Bethesda, MD 20892-4062. E-mail: sba@helix.nih.gov.

DOI:10.1523/JNEUROSCI.0531-04.2004

Copyright (C) 2004 Society for Neuroscience $\quad 0270-6474 / 04 / 245611-12 \$ 15.00 / 0$
}

death, overstimulation of neurons evokes the release of proapoptotic proteins from mitochondria (Budd et al., 2000; Luetjens et al., 2000; Brustovetsky et al., 2002; Yu et al., 2002) and results in delayed death by apoptosis (Ankarcrona et al., 1995; Bonfoco et al., 1995; Budd et al., 2000), although the underlying mechanisms remain controversial.

Based mainly on in vitro observations, one currently popular model consistent with excitotoxic apoptosis proposes that mitochondrial $\mathrm{Ca}^{2+}$ overload triggers an injury response, possibly through a mitochondrial permeability transition (MPT), that leads to the loss of $\Delta \Psi_{\mathrm{m}}$, permeabilization of the inner mitochondrial membrane, swelling of the matrix and outer membrane rupture, followed by release of apoptogenic proteins (Kroemer and Reed, 2000; Bernardi et al., 2001; Friberg and Wieloch, 2002; Mattson and Kroemer, 2003). Such mechanisms present a paradox, however, in that the destruction of mitochondria impairs the ATP supplies that are essential for activation of energydependent apoptotic pathways. One proposed solution envisions that only a subpopulation of mitochondria undergoes a permeability transition and releases apoptogens, whereas the remaining, undamaged mitochondria respire normally and produce ATP (Crompton, 2000).

In previous work, we quantitatively measured calcium accu- 
mulation by individual mitochondria in $\mathrm{K}^{+}$-depolarized sympathetic neurons (Pivovarova et al., 1999) and in synaptically activated hippocampal dendrites (Pivovarova et al., 2002) and, in both cases, observed a striking heterogeneity from one mitochondrion to another with regard to the amounts of $\mathrm{Ca}^{2+}$ taken up and sequestered. These observations led to the hypothesis that during excitotoxic stimulation some neuronal mitochondria will accumulate more $\mathrm{Ca}^{2+}$ than others and that these "overloaded" mitochondria might be a source of apoptogenic proteins. To test this idea, we used cultured hippocampal neurons to investigate the ionic, structural, and functional changes in individual mitochondria that follow injurious NMDA stimulation. The results demonstrate that NMDA overstimulation causes calcium overload only in a subpopulation of mitochondria and that these mitochondria undergo subsequent swelling, outer membrane rupture, and cytochrome $c$ release. Remaining mitochondria apparently can resume normal functions, thereby creating conditions favorable for the downstream apoptotic reactions that lead to delayed cell death.

\section{Materials and Methods}

Hippocampal neuronal culture. Cultures of rat hippocampal neurons, grown on top of a feeder layer of glial cells, were prepared as described previously (Mayer et al., 1989; Lu et al., 1998). Briefly, suspensions of a mixed population of brain cells prepared by papain dissociation of hippocampi from $21 \mathrm{~d}$ embryonic Sprague Dawley rats were plated onto 2-week-old glial feeder layers at a density of 250,000 per $35 \mathrm{~mm}$ dish. Cells were fed twice weekly with half changes of MEM supplemented with $5 \%(\mathrm{v} / \mathrm{v})$ heat-inactivated horse serum, 1\% (v/v) FBS, 2 mm Glutamax (all from Life Technologies, Gaithersburg, MD), $136 \mu \mathrm{M}$ uridine, $54 \mu \mathrm{M}$ 2-deoxy-5-fluoro-uridine, and the growth factor mixture N3 (Mayer et al., 1989). Cells were maintained in a $37^{\circ} \mathrm{C}$ incubator with $10 \%$ $\mathrm{CO}_{2}$. Experiments were performed on cultures $17-21 \mathrm{~d}$ old. All procedures were in accordance with the NIH Guide for the Care and Use of Laboratory Animals and were approved by the National Institutes of Health Animal Care and Use Committee.

Excitotoxic injury assays. To induce excitotoxicity, cultures were washed in a $\mathrm{Mg}^{2+}$-free HEPES-buffered saline solution (HBSS) containing (in mM) $137 \mathrm{NaCl}, 10 \mathrm{HEPES}, 1.1 \mathrm{CaCl}_{2}, 5.4 \mathrm{KCl}, 0.3 \mathrm{Na}_{2} \mathrm{HPO}_{4}, 0.22$ $\mathrm{KH}_{2} \mathrm{PO}_{4}, 16$ glucose, and 20 sucrose ( 320 mOsm; $\mathrm{pH} 7.4$ ) supplemented with $10 \mu \mathrm{M}$ glycine and $500 \mathrm{~nm}$ TTX. Cells were then incubated in $200 \mu \mathrm{M}$ NMDA in HBSS for $20 \mathrm{~min}$ at $23^{\circ} \mathrm{C}$. After treatment, cultures were washed with HBSS and returned to the original culture medium supplemented with $20 \mu \mathrm{M}$ dizocilpine (MK-801) to prevent residual activation.

Degenerating cells were identified by light and electron microscopy. For light microscopy, nuclear chromatin was stained with $1 \mu \mathrm{g} / \mathrm{ml}$ Hoechst 33258 (Sigma, St. Louis, MO) in HBSS. In degenerating neurons, nuclei decreased in size and became intensely fluorescent, in contrast to the larger, pale nuclei of healthy cells. Cell death was assayed at $18-24 \mathrm{hr}$ either by trypan blue $(0.2 \%)$ or propidium iodide (PI; 3.3 $\mu \mathrm{g} / \mathrm{ml}$ ) staining. For conventional electron microscopy, cultured cells on glass or plastic coverslips were fixed with $4 \%$ glutaraldehyde in cacodylate buffer, followed by post-fixation with $1 \% \mathrm{OsO}_{4}$. Cells were embedded in epoxy resin, sectioned, and counterstained using standard procedures. Alternatively, hippocampal neuron cultures grown in gold specimen carriers were high-pressure frozen at 2100 bar by means of a Baltec HM10 high-pressure freezing machine (Technotrade International, Manchester, NH). Frozen samples were processed in a Leica EMAFS freeze-substitution machine (Leica Microsystems, Bannockburn, IL) in saturated uranyl acetate and $2 \%$ acrolein in acetone and stained with saturated uranyl acetate and $0.025 \%$ hafnium chloride before embedding in Araldite resin. Sections were viewed in a 1200 transmission electron microscope (JEOL, Peabody, MA). Images were recorded digitally by means of an XR-100 CCD camera (Advanced Microscopy Techniques, Danvers, MA).

Fluorescence microscopy. For calcium imaging, neurons were loaded with the low-affinity $\mathrm{Ca}^{2+}$-sensitive dye Fluo-4FF (Molecular Probes,
Eugene, OR) by incubation in $5 \mu \mathrm{M}$ Fluo-4FF AM ester in HBSS for 30 min and subsequently imaged using a confocal fluorescence microscope (Zeiss 410 LSM; $25 \times$ and $40 \times$ water-immersion objectives, fluorescein optics; Zeiss, Thornwood, NY). Image stacks from 10-40 neurons per experiment were recorded every $15 \mathrm{sec}$ for up to $2 \mathrm{hr}$. Somatic regions of projection images of individual cells were chosen for quantitation of fluorescence intensity using NIH Image software (available at http:// rsb.info.nih.gov/nih-image). Data are given as $\left(\mathrm{F} / \mathrm{F}_{0}\right)$ (i.e., fluorescence intensity relative to initial fluorescence before stimulation).

To monitor changes in mitochondrial structure, cells were transfected on the 6-7 d in vitro with the mitochondrially targeted green fluorescent protein (GFP) derivative mito-eYFP (enhanced yellow fluorescent protein) (Clontech, Palo Alto, CA) using Effectene transfection reagent (Qiagen, Valencia, CA), following the protocol recommended by the manufacturer. Transfection efficiency was typically $\sim 1 \%$. Images were recorded using a Zeiss 510 laser scanning confocal microscope [63×; 1.4 numerical aperature (NA) objective; excitation, $514 \mathrm{~nm}$; emission, $>560 \mathrm{~nm}$ ].

Tetramethylrodamine ethyl ester (TMRE) is a cationic, lipophilic dye that accumulates in the mitochondrial matrix. The ratio of TMRE fluorescence from the mitochondria-rich cytoplasm to that from the nucleus provides a reliable estimate of the mitochondrial membrane potential $\Delta \Psi_{\mathrm{m}}$ in single cells (Luetjens et al., 2000). Cells were loaded in $0.1 \mu \mathrm{M}$ TMRE (Molecular Probes) in HBSS for $20 \mathrm{~min}$, and parallel sister cultures were imaged briefly on the Zeiss 510 confocal microscope $(63 \times ; 1.4$ NA objective; excitation, $543 \mathrm{~nm}$; emission, $>560 \mathrm{~nm}$ ), the first culture before and immediately after NMDA simulation and the second culture $2 \mathrm{hr}$ later. Imaging two parallel cultures once each rather than the same cells twice avoids photodamage and possible TMRE toxicity (Duchen, 2000). Brief imaging and low loading concentrations were also advantageous. Fluorescence was quantified using NIH Image software.

Electron probe $x$-ray microanalysis. For electron probe $\mathrm{x}$-ray microanalysis (EPMA), cultured cells on plastic coverslips were rapidly frozen in liquid nitrogen-cooled liquid ethane by means of a custom-designed plunge-freezing device (Zeiss, Oberkochen, Germany). Frozen coverslips were transferred to the working chamber of a Leica Ultracut S/FCS ultracryomicrotome precooled to $-160^{\circ} \mathrm{C}$ and cut into small pieces to fit on 3 $\mathrm{mm}$ diameter aluminum pins. Pieces of cut coverslips were "cryoglued" onto pins using a modification of the method of Richter (1994). Pieces were oriented and embedded in a mixture of 2-propanol and ethanol $(6: 1)$ at a temperature $\left(-135^{\circ} \mathrm{C}\right)$ at which it is a viscous liquid. Subsequently, the cryoglue was solidified by lowering the temperature to $<-160^{\circ} \mathrm{C}$, and cryosectioning was then performed essentially as described previously (Buchanan et al., 1993). Sections mounted on carbon/ Formvar-coated grids were cryotransferred into an EM912 Omega electron microscope (LEO Electron Microscopy, Thornwood, NY), freezedried at $\sim-110^{\circ} \mathrm{C}$, and recooled to $\sim-170^{\circ} \mathrm{C}$ before imaging and analysis. Digital low-dose, zero-loss images of freeze-dried sections were recorded by means of a ProScan $2 \mathrm{kx} 2 \mathrm{k}$ slow-scan CCD camera controlled by AnalySIS software (Soft Imaging System GmbH, Munster, Germany). $\mathrm{x}$-ray spectra were recorded (at $\sim-170^{\circ} \mathrm{C}$ for $100 \mathrm{sec}$ each at $\sim 5 \mathrm{nA}$ probe current using a focused probe with a diameter of $100 \mathrm{~nm}$ ) by means of a Linksystem Pentafet EDX detector (Oxford Instruments, Concord, MA) and were subsequently processed and quantified by established procedures (Shuman et al., 1976; Hall and Gupta, 1983; Pivovarova et al., 1999) using DeskTop Spectrum Analyzer software for Macintosh (C. E. Fiori, C. R. Swyt, and R. L. Myklebust, Office of Standard Reference Data, National Institute of Standards and Technology, Gaithersburg, MD; 1993). The Simplex fitting routine and Hall peak/ continuum method were used to quantify the total (i.e., free plus bound, elemental concentrations of $\mathrm{Na}, \mathrm{Mg}, \mathrm{P}, \mathrm{S}, \mathrm{Cl}, \mathrm{K}$, and $\mathrm{Ca}$ ). Concentrations are given in millimoles per kilogram of dry weight.

Electron microscopic immunocytochemistry. Pre-embedding immunocytochemistry was performed essentially as described (Tanner et al., 1996). Cells were fixed with $4 \%$ paraformaldehyde in $0.1 \mathrm{~m}$ phosphate buffer at $\mathrm{pH} 7.4$ for $20 \mathrm{~min}$, washed, permeabilized, and incubated with a purified mouse anti-cytochrome $c$ monoclonal antibody (BD Biosciences, San Diego, CA), followed by incubation with a nanogoldconjugated secondary antibody (Nanoprobes, Yaphank, NY) and silver enhancement (HQ kit; Nanoprobes). Coverslips were further processed 
by treatment with $0.2 \% \mathrm{OsO}_{4}$, dehydration, and embedding in an epoxy resin.

Statistics. Statistical differences $(p<0.05)$ among experimental groups were, in general, determined using one-way ANOVA, followed when appropriate by tests for multiple comparisons. EPMA sampling strategy aimed to acquire five random analyses per cell for each compartment (cytoplasm and mitochondria) from five random cells per culture from at least three different platings. In practice, the actual number of analyses in a given preparation varied because of the variable abundance of mitochondria but was always three or more analyses per cell. The final data set was unbalanced and was treated as such for statistical analysis. ANOVA indicated that in all cases there were no differences between cultures from the same experimental group; therefore, data from individual cultures were pooled to calculate group means. Group means and SEM are based on the number of organelles in a group. For normally distributed data, one-way ANOVA was followed by the Bonferroni test for multiple comparisons. For data that were not normally distributed (e.g., mitochondrial Ca after NMDA exposure), the Mann-Whitney $U$ test or Kruskal-Wallis nonparametric ANOVA with Dunn's test for multiple comparisons of unbalanced data were used. Statistical analyses were performed using InStat software (GraphPad Software, San Diego, CA).

Chemicals, reagents, drugs, and nomenclature. Unless stated otherwise, reagents were purchased from Sigma, including TTX, glycine, NMDA, (5R,10S)-(+)-5-methyl-10,11-dihydro-5H-dibenzo[a,d]cyclohepten5,10-imine maleate (MK-801), carbonyl cyanide p-(trifluoromethoxy) phenylhydrazone (FCCP), and cyclosporin A (CsA). Bongkrekic acid (BA) was from Calbiochem (La Jolla, CA).

Throughout this paper, elemental symbols with the oxidation state specified (e.g., $\mathrm{Ca}^{2+}$ ) are used conventionally to indicate ions in the free, water-solvated state, whereas symbols without such specification (e.g., $\mathrm{Ca}$ ) refer to the element without regard to whether it is free or bound and are mainly used to indicate total concentrations as measured by EPMA.

\section{Results \\ NMDA-induced changes in mitochondrial structure and function precede delayed cell death}

Mild excitotoxic insult to cultured cortical neurons leads to delayed death by a mechanism that has many characteristics of classical apoptotis (Ankarcrona et al., 1995; Bonfoco et al., 1995; Budd et al., 2000; Yu et al., 2002). Using a protocol for excitotoxic overstimulation of cultured hippocampal neurons (200 $\mu \mathrm{M}$ NMDA for $20 \mathrm{~min}$ ) that is comparable with those of previous studies, we observed several NMDA-induced changes, especially to the mitochondria of these neurons. Thus, confocal microscopy of cells transfected with mito-eYFP revealed that in prestimulus neurons, mitochondria appear as long, thin rods; individual rods were readily distinguished in both cell bodies and neuronal processes (Fig. 1, top row). After NMDA stimulation, many mitochondria changed shape to discreet, punctate dots, consistent with swelling or fragmentation or both, fragmentation, but a significant fraction remained rod-like (Fig. 1, top right, arrows). No change was observed during control exposure to NMDA-free buffer (data not shown). These results are consistent with a recent study reporting mitochondrial morphological changes in cortical neurons after glutamate stimulation (Rintoul et al., 2003) and with previous studies that demonstrated dramatic swelling of neuronal mitochondria either under excitotoxic conditions (Mattson et al., 1993; Dubinsky and Levi, 1998; Zeng and Xu, 2000) or as a direct result of $\mathrm{Ca}^{2+}$ accumulation in isolated mitochondria (Dubinsky and Levi, 1998; Gogvadze et al., 2001; Brustovetsky et al., 2002).

By $2 \mathrm{hr}$ after stimulus removal, the majority of neurons had recovered normal morphology, although a fraction of cells $(\sim 20 \%)$ failed to recover. These cells were positive for PI (data not shown), indicating that they must have died early, presumably by acute necrosis. Such cells were not considered further. In cells that did recover, eYFP-tagged mitochondria had also recovered their normal structure (Fig. 1, second row).

Parallel, reversible changes were also observed in the mitochondrial membrane potential $\left(\Delta \Psi_{\mathrm{m}}\right)$. Recent evidence suggests that after excitotoxic stimulation, the $\Delta \Psi_{\mathrm{m}}$ of neuronal mitochondria undergoes brief depolarization, followed by a transient recovery before permanent, but delayed, loss (Luetjens et al., 2000). Changes in $\Delta \Psi_{\mathrm{m}}$ after NMDA stimulation were estimated using TMRE, a voltage-sensitive fluorescent dye that is selective for mitochondria. To limit photodamage, cells were loaded with low concentrations $(0.1 \mu \mathrm{M})$ of TMRE and illuminated only briefly during imaging. TMRE fluorescence was almost completely lost from the majority of neurons during NMDA exposure (Fig. 1), indicating a strong depolarization of $\Delta \Psi_{\mathrm{m}}$ in the majority of mitochondria within every cell. In contrast, control cells that were loaded, incubated, and illuminated identically but not exposed to NMDA maintained bright TMRE fluorescence. After a $2 \mathrm{hr}$ recovery, TMRE fluorescence in NMDA-treated neurons (excluding those that died acutely) was not significantly different from controls, implying that after stimulus removal the majority of mitochondria had recovered $\Delta \Psi_{\mathrm{m}}$ and, presumably, functional competence.

Although the changes in mitochondrial structure and $\Delta \Psi_{\mathrm{m}}$ were mostly reversible, we found that as early as $6 \mathrm{hr}$ after stimulation, a significant fraction of surviving neurons ( $37 \pm 5 \%$ ) already displayed at the light microscopy level certain morphological features typical of degeneration, including cytoplasmic and nuclear shrinkage and chromatin condensation (Fig. 1, bottom row). At this time point, these cells were not permeable to PI, ruling out necrotic cell death. By 18-24 hr after stimulus, $44 \pm$ $5 \%$ of cells had a degenerative phenotype, and many of these neurons had become PI positive (Fig. 1, bottom right), presumably because of secondary necrosis (Orrenius et al., 2003). These observations establish that the stimulus used here is highly effective at inducing delayed cell death and implicate events during or shortly after the acute phase of stimulation as triggers for the death sequence.

Structural changes in somatic mitochondria were next examined at a finer level of detail by electron microscopy of cryosections of unfixed, rapidly frozen cultures (Fig. 2); rapidly frozen preparations were useful here because they capture the instantaneous structure of cells and organelles, as well as their elemental composition (see below), thereby avoiding artifacts that might arise from slow chemical fixation. Under control conditions, mitochondria appeared as typical elongated rods with diameters of $\sim 150 \mathrm{~nm}$. After NMDA stimulation, the majority of neurons displayed massive dilation of the endoplasmic reticulum and swelling of mitochondria, although, importantly, only a subpopulation of mitochondria swells. Many mitochondria changed shape to oval or round, and their diameter increased to 300-500 $\mathrm{nm}$, but not all mitochondria were swollen to the same extent. In the majority of neurons, there typically were several highly swollen mitochondria scattered among those that were swollen little, if at all. The fraction of severely swollen mitochondria varied widely from cell to cell but averaged $30-40 \%$. These observations indicate that the response of individual mitochondria is highly variable. In contrast to the evident effects of NMDA on neurons, no NMDA-dependent structural changes were observed in glial cells, which therefore served as internal controls to confirm the specific action of NMDA only on neurons. The specificity of NMDA stimulation was also indicated by coapplication of the NMDA antagonist MK-801 (20 $\mu \mathrm{M})$, which abolished stimulusdependent structural changes (data not shown). 
Consistent with results from confocal microscopy, cell and organelle swelling was mostly reversible. After a $2 \mathrm{hr}$ recovery period, the majority of cells were morphologically normal, and most mitochondria had recovered volume regulation, although some cells still contained structurally altered mitochondria. At $6 \mathrm{hr}$ after stimulation, electron microscopy confirmed the presence of at least two types of cells, those with normal morphology and degenerating cells with apoptotic-like ultrastructure, including shrunken, partially clear cytoplasm and shrunken nuclei with condensed, fragmented and marginated chromatin (Fig. 2). These cells were further characterized by undamaged plasma membranes and a reduced complement of slightly swollen, possibly fragmented, but otherwise well preserved mitochondria.

\section{Calcium-dependent mitochondrial dysfunction and cell death}

We next asked whether acute NMDAinduced changes in mitochondrial structure and function were $\mathrm{Ca}^{2+}$ dependent. NMDA-induced changes in the concentration of cytosolic free $\mathrm{Ca}^{2+}\left(\left[\mathrm{Ca}^{2+}\right]_{\mathrm{i}}\right)$ were recorded using the low-affinity fluorescent $\mathrm{Ca}^{2+}$ probe Fluo-4FF. A typical time course for $\left[\mathrm{Ca}^{2+}\right]_{\mathrm{i}}$ during and after NMDA stimulation exhibits an initial fast rise and decay, followed by a sustained elevation that slowly recovers to prestimulus levels after NMDA removal (Fig. 3A). This biphasic behavior with a prolonged recovery period is consistent with results from previous studies (Dubinsky,1993; Schinder et al., 1996). In addition, the second, sustained phase correlates well with mitochondrial swelling and loss of $\Delta \Psi_{\mathrm{m}}$. Total (as opposed to free) concentrations of $\mathrm{Ca}$ as well as those of $\mathrm{Na}, \mathrm{K}, \mathrm{Cl}, \mathrm{P}$, and $\mathrm{Mg}$ in neuronal cytoplasm and mitochondria were measured by EPMA of freezedried cryosections prepared from cultures that were plunge-frozen immediately after 20 min of stimulation, as well as without stimulation and after appropriate recovery times. After NMDA exposure, neurons, in general, contained highly elevated concentrations of $\mathrm{Na}, \mathrm{Cl}$, and $\mathrm{Ca}$, whereas $\mathrm{K}$ was almost completely lost (Table 1; Fig. $3 B, C)$. In agreement with previous reports on acute $\mathrm{Na}$ and $\mathrm{K}$ changes after excitotoxic stimulation (Choi, 1987; Kiedrowski et al., 1994), cytoplasmic concentrations of total $\mathrm{Na}$ and $\mathrm{Ca}$ increased, whereas $\mathrm{K}$ fell more than 10-fold compared with typical values for resting neurons. Changes in the concentrations of diffusible cations in mitochondria after NMDA stimulation paralleled those in the cytoplasm, with a reversed $\mathrm{Na} / \mathrm{K}$ ratio (Table 1 ; Fig. $3 C$ ) and an average elevation of mitochondrial total calcium

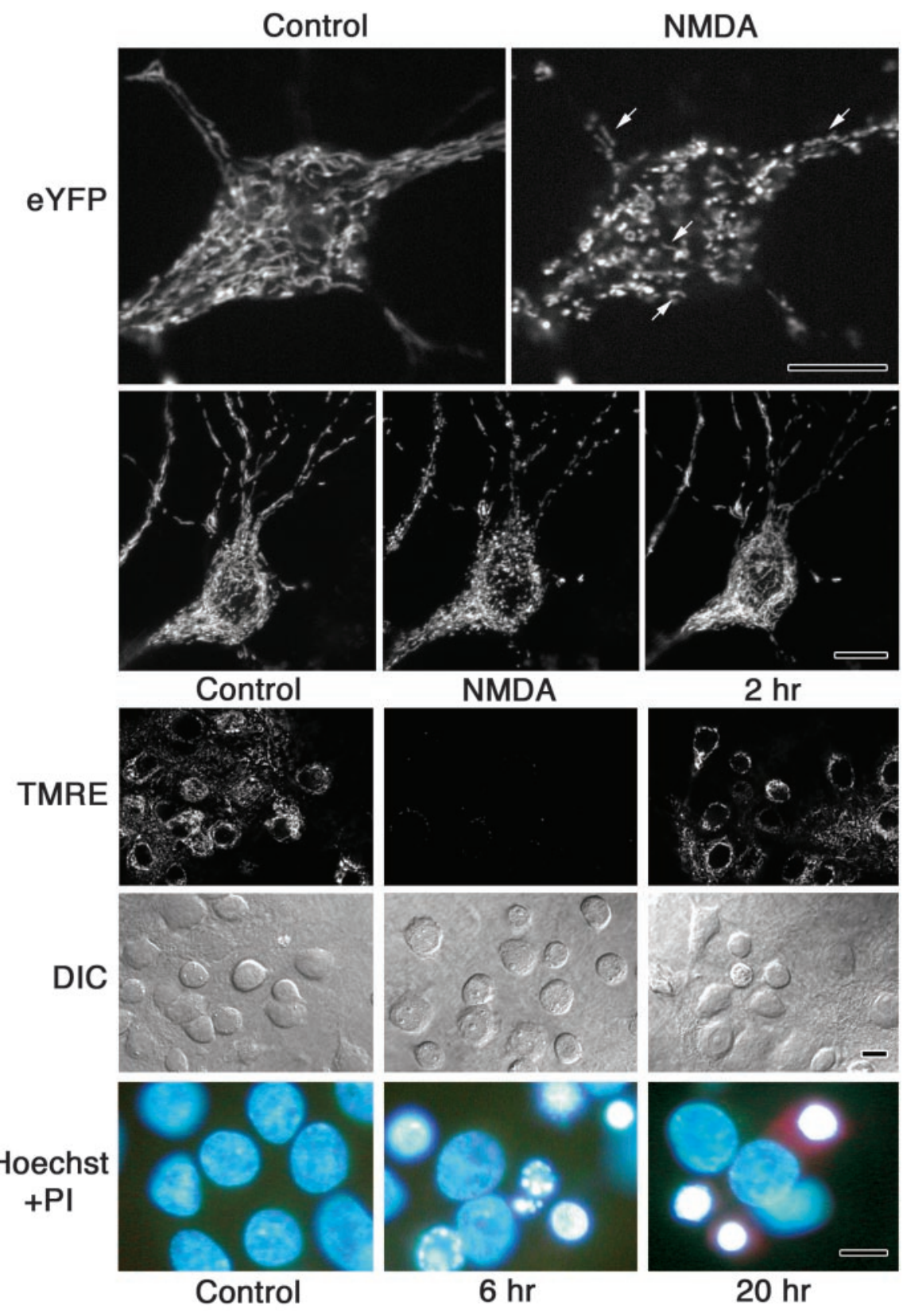

Figure 1. NMDA stimulation alters mitochondrial structure and function and promotes delayed cell death. First row, Confocal fluorescence single-slice images of a typical cultured hippocampal neuron expressing mito-eYFP. The field illustrates distribution of mitochondria in the soma and in proximal processes. Under prestimulus conditions, individual eYFP-tagged mitochondria are readily seen in both the soma and processes as long bright rods. After NMDA stimulation, most eYFP-tagged mitochondria change shape to discreet, punctate dots, but many (arrows) remain rod-like. Second row, In the majority of mitochondria, normal shape returns $2 \mathrm{hr}$ after stimulus removal. Shape recovery is most evident for mitochondria overlying the nucleus and in those near the origin of the process directed upward. Third and fourth rows, Confocal fluorescence images of TMRE-labeled neurons and corresponding differential interference contrast images under control conditions, immediately after NMDA stimulation, and $2 \mathrm{hr}$ after stimulus removal reveal the reversible loss of mitochondrial membrane potential. Under control conditions, neurons emit a strong TMRE fluorescence signal from the cytoplasm but not from the nucleus. In neurons stimulated with NMDA, TMRE fluorescence is very low but is strong again $2 \mathrm{hr}$ after stimulus removal, reflecting transient depolarization of the majority of mitochondria. Bottom row, Fluorescence images of hippocampal neurons stained with Hoechst and PI. Control cells have uniformly large nuclei with a normal chromatin pattern. At $6 \mathrm{hr}$ after stimulation, degenerating cells ( $37 \pm 5 \%$ of all neurons) can be distinguished by their small bright nuclei. At $20 \mathrm{hr}$ after stimulation, degenerating cells are positive for $\mathrm{PI}$ (red), reflecting dead cells with disrupted plasma membranes. Scale bars, $10 \mu \mathrm{m}$. 


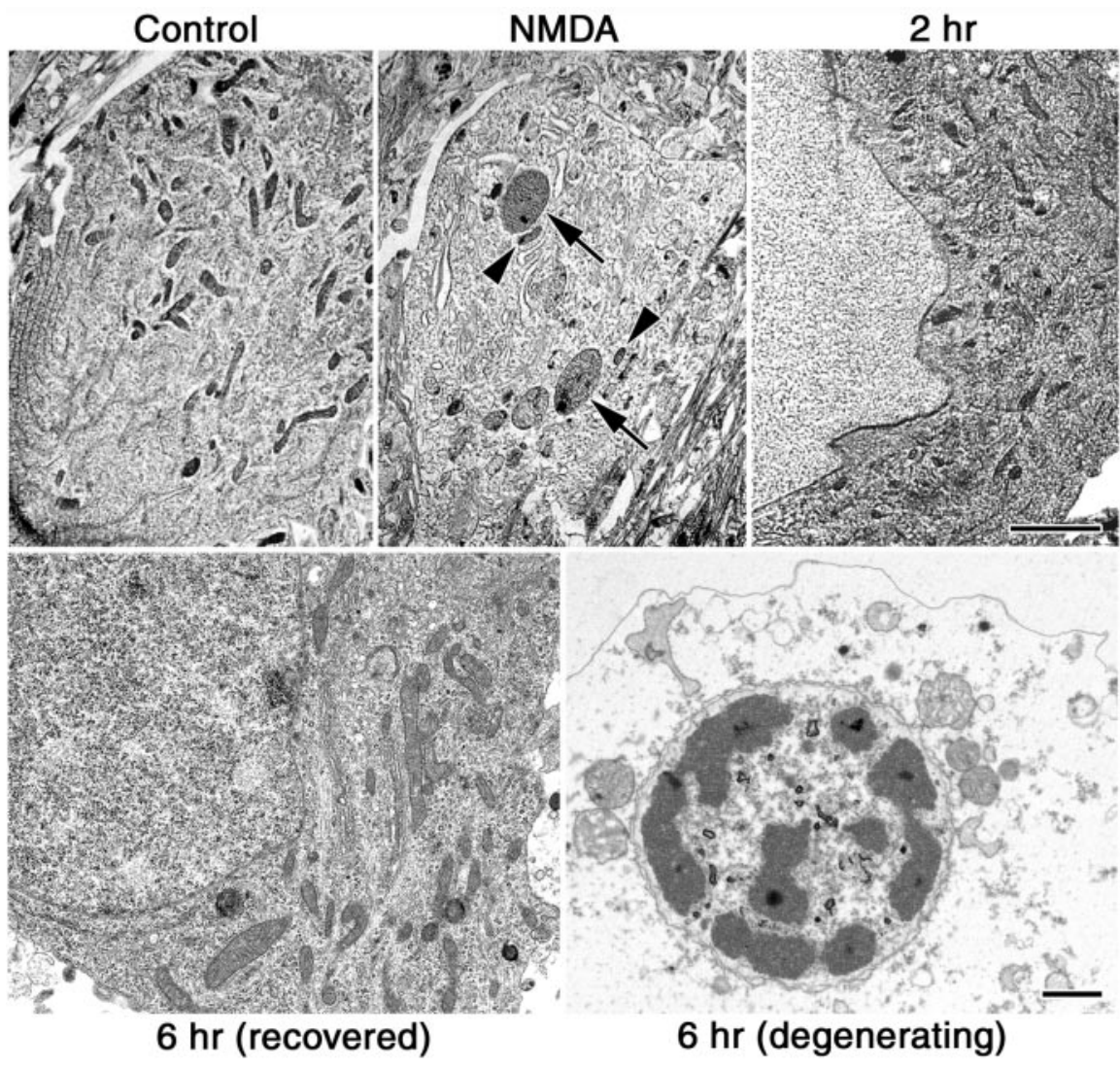

Figure 2. NMDA stimulation induces variable, reversible changes in mitochondrial ultrastructure. Top row, Digital transmission electron micrographs of freeze-dried cryosections prepared from unfixed, quick-frozen cell cultures. The field illustrates typical views of neuronal cell bodies containing numerous mitochondria. In control neurons as well as in neurons $2 \mathrm{hr}$ after stimulus, mitochondrial structure is normal. In contrast, an NMDA-stimulated neuron has several strongly swollen mitochondria (arrows), whereas the shape of others (arrowheads) does not noticeably change. Digital images of cryosections were recorded at low dose and low temperature in the zero-loss mode of an energy-filtering microscope. Scale bar, $2 \mu \mathrm{m}$. Bottom row, Transmission electron micrographs of conventionally fixed, stained, and plastic-embedded preparations of recovered and degenerating neurons $6 \mathrm{hr}$ after NMDA stimulation. A recovered neuron has structurally normal mitochondria and nucleus. A representative degenerating neuron has a reduced complement of mitochondria and a typically small, shrunken nucleus with fragmented, condensed, and marginated chromatin, whereas the plasma membrane is still intact. Scale bar, $1 \mu \mathrm{m}$.

Like NMDA-induced changes in structure and $\left[\mathrm{Ca}^{2+}\right]_{\mathrm{i}}$, elemental changes in most neurons were reversible. Thus, by $2 \mathrm{hr}$ after stimulus removal, the cytoplasm of neurons that survived the acute phase of stimulation $(\sim 80 \%)$ had, in general, returned to prestimulus elemental composition (Fig. 3B). At this time, most mitochondria in cells with restored structure and ion homeostasis had also recovered normal structure and elemental composition. Importantly, however, average $[\mathrm{Ca}]_{\text {mito }}$ across multiple cells remained slightly, but significantly, elevated (7.4 $\mathrm{mmol} / \mathrm{kg}$, Table 1$)$. This elevation of average basal $[\mathrm{Ca}]_{\text {mito }}$ arises because $[\mathrm{Ca}]_{\text {mito }}$ in a fraction of mitochondria did not return to control levels in $\sim 35 \%$ of cells. Most mitochondria in this subset of cells had normal ultrastructure, but the $\sim 17 \%$ that still retained a high Ca load appeared to be irreversibly damaged and in the process of disintegration and autophagic removal (Lemasters et al., 2002). It is plausible that the persistence of injured mitochondria at this late time after overstimulation marks the cells that were most vulnerable.

Six hours after stimulus removal, the ion composition of both cytoplasm and mitochondria in recovered neurons with normal morphology was not different from prestimulus composition (Table 1). Degenerating neurons that were evident at this time had high $\mathrm{Na}$ and $\mathrm{Ca}$ and low $\mathrm{K}$ in both cytoplasm and mitochon- dria (Table 1), indicating that both the $\mathrm{Na}^{+} / \mathrm{K}^{+}$-ATPase and the plasma membrane $\mathrm{Ca}^{2+}$-ATPase had become inactive. Note that, on average, the mitochondria of these dying neurons still contained high Ca (Table 1).

Consistent with the previously mentioned absence of NMDA-induced structural effects on glia, the elemental composition of glial cells was also unaffected by NMDA stimulation. During NMDA exposure, glia maintained normally low $\mathrm{Na}$ and $\mathrm{Ca}$ and high $\mathrm{K}$ in both cytoplasm (30 \pm 6 , $0.8 \pm 0.7$, and $370 \pm 10 \mathrm{mmol} / \mathrm{kg}$ dry weight, respectively) and mitochondria $(10 \pm 3,0.5 \pm 0.4$, and $200 \pm 7 \mathrm{mmol} / \mathrm{kg}$, respectively). As a further indication of NMDA specificity, coapplication of MK801 prevented NMDA-induced elemental changes in neurons (Table 1).

The parallel time course of mitochondrial structure/function changes and calcium elevation and decline implies that mitochondrial perturbations are $\mathrm{Ca}^{2+} \mathrm{de}-$ pendent. The $\mathrm{Ca}^{2+}$ dependence of acute NMDA-induced changes, as well as the role of $\mathrm{Ca}^{2+}$ in cell death, was further indicated by the neuroprotective effect of the protonophore FCCP, which is known to inhibit mitochondrial $\mathrm{Ca}^{2+}$ accumulation by depolarizing $\Delta \Psi_{\mathrm{m}}$. The effect of FCCP on stimulated $\left[\mathrm{Ca}^{2+}\right]_{i}$ changes, as measured with Fluo-4FF, indicates a significant role for mitochondria in cytosolic $\mathrm{Ca}^{2+}$ handling. Thus, coapplication of FCCP with NMDA modified the biphasic $\mathrm{Ca}^{2+}$ response induced by NMDA alone to a single larger $(\sim 30 \%)$ and more sustained $\left[\mathrm{Ca}^{2+}\right]_{\mathrm{i}}$ rise, followed by an accelerated recovery on stimulus removal (Fig. $3 A$ ). Both observations are explained by inhibition of mitochondrial $\mathrm{Ca}^{2+}$ uptake, in that normally a stimulated $\left[\mathrm{Ca}^{2+}\right]_{\mathrm{i}}$ rise is blunted by mitochondrial $\mathrm{Ca}^{2+}$ uptake, whereas the recovery is prolonged by post-stimulus release of this intramitochondrial pool (Friel, 2000). Neither mechanism operates when mitochondrial $\mathrm{Ca}^{2+}$ uptake is inhibited. Impaired mitochondrial $\mathrm{Ca}^{2+}$ uptake in the presence of FCCP is also indicated by the $>300 \%$ decrease in NMDA-stimulated mitochondrial Ca accumulation, paralleled by elevation of total cytosolic Ca (again 30\%) (Table 1 ; Fig. $3 B, C$ ). Importantly, the conditions achieved in the presence of FCCP, higher cytosolic and lower mitochondrial Ca, were less toxic than with NMDA alone; cell viability was improved by $75 \%$ (Fig. 3A), consistent with similar findings for cortical neurons (Stout et al., 1998). Thus, survival of hippocampal neurons appears to depend less on the magnitude of $\left[\mathrm{Ca}^{2+}\right]_{\mathrm{i}}$ elevations and more on the size of the mitochondrial Ca load.

We next examined the role of $\mathrm{Ca}$ overload in mitochondrial swelling, which is important because swelling is thought to be an essential step in the sequence leading to apoptogen release. Mitochondrial swelling did not occur in cells that were NMDA stimulated in $\mathrm{Ca}^{2+}$-depleted (1 mM EGTA) extracellular medium (data not shown). Similarly, NMDA stimulation in a medium in which $\mathrm{Ba}^{2+}$, which can permeate NMDA receptors but enters 
A
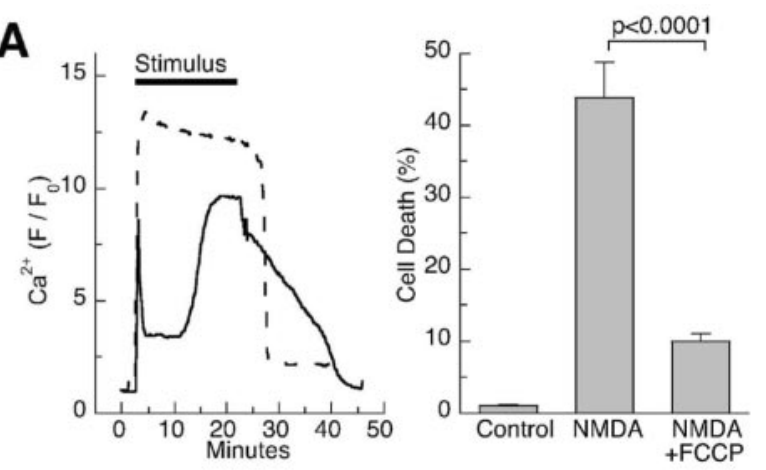

B
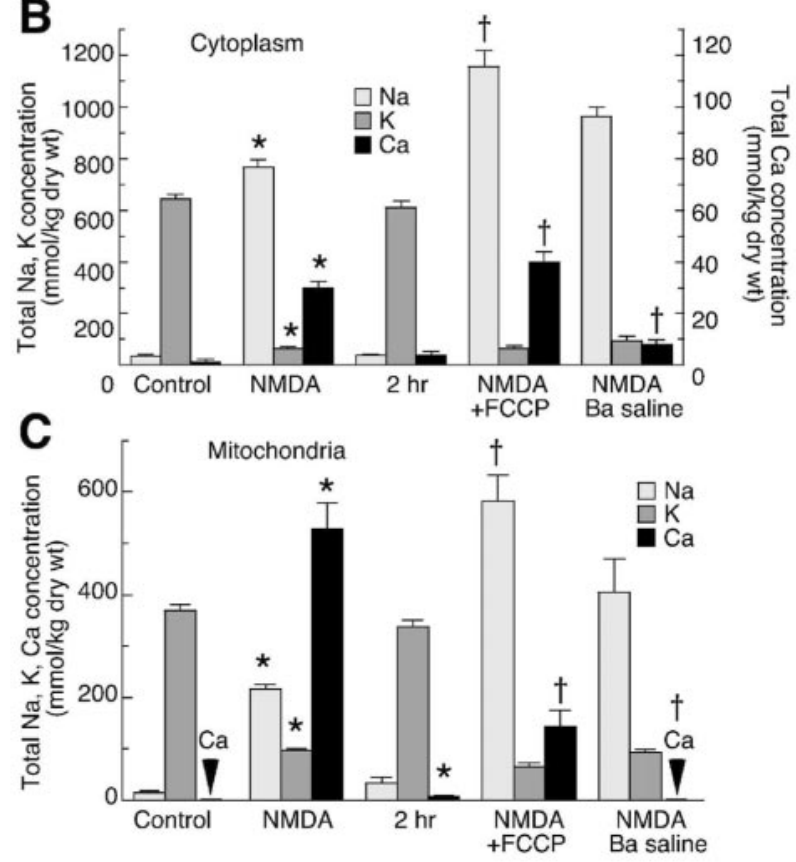

Figure 3. NMDA-induced changes in the ionic composition and calcium dependence of neuronal survival. $A$, Left, Cytosolic free $\mathrm{Ca}^{2+}$, as measured with the low-affinity probe Fluo-4FF and given as fluorescence intensity $(F)$ normalized to baseline fluorescence $\left(F_{0}\right)$, undergoes two phases of elevation during NMDA exposure (solid line). The first, at the onset of stimulation, is a true transient, followed by a second phase during which cytosolic free $\mathrm{Ca}^{2+}$ plateaus at a relatively high level for the duration of the stimulus. The presence of FCCP (750 nM) changes the shape of NMDA-evoked transients, increasing the amplitude and enhancing recovery in a manner consistent with the elimination of mitochondrial $\mathrm{Ca}^{2+}$ uptake and release (dashed line). Right, NMDA-induced excitotoxic cell death, as measured by trypan blue exclusion $20-24 \mathrm{hr}$ after stimulation, significantly decreases in the presence of FCCP. Difference by $t$ test, $p<0.0001$. $B$, $C$, In control neurons, total $N$ a, $K$, and Ca concentrations are consistent with known values for resting pyramidal neurons (Pozzo-Miller et al., 1997). Immediately after NMDA exposure, cytosolic average concentrations of total $\mathrm{Na}$ and Ca increase, whereas the concentration of $\mathrm{K}$ falls. Cells recover from Ca loading and reestablish normal cytosolic $\mathrm{Na} / \mathrm{K}$ ratios and $\mathrm{Ca}$ concentrations by $2 \mathrm{hr}$ after stimulus removal. In general, average concentrations of $\mathrm{Na}$ and $\mathrm{K}$ in mitochondria follow NMDA-stimulated changes in the cytoplasm, but mitochondrial Ca elevations are quantitatively much higher and remain slightly, but significantly, elevated after a $2 \mathrm{hr}$ recovery period. Immediately after NMDA exposure in the presence of $\mathrm{FCCP}, \mathrm{Na}$ and $\mathrm{K}$ changes in both the cytoplasm and mitochondria are qualitatively similar to those induced by NMDA only, although Na increases are much larger. Importantly, however, Ca accumulation in mitochondria is substantially reduced whereas cytosolic concentrations of total $\mathrm{Ca}$ increase. When $\mathrm{Ba}^{2+}$ is substituted for $\mathrm{Ca}^{2+}$ in the incubation medium, NMDA stimulation induces qualitatively similar changes in $\mathrm{Na}$ and $\mathrm{K}$ concentrations. Note that under these conditions, cytosolic Ca elevations were mainly suppressed but not eliminated, probably because a lowlevel of $\mathrm{Ca}^{2+}$ entry persisted because of residual $\mathrm{Ca}^{2+}$ in the medium; nonetheless, mitochondrial Ca was not significantly increased, nor was Ba detected in mitochondria. Note different ordinate scales in C. Concentrations of total $\mathrm{Na}, \mathrm{K}$, and Ca were measured by EPMA on freeze-dried cryosections prepared from quick-frozen hippocampal cultures; data are given as mean \pm SEM (millimoles per kilogram of dry weight). Asterisks indicate statistical differences $(p<$ $0.05)$ between control and stimulated cells; daggers indicate differences $(p<0.05)$ relative to NMDA-stimulated cells. See Table 1 and Materials and Methods for details of statistical analysis. mitochondria only slowly (see Dubinsky and Levi, 1998, and references therein), had been substituted for $\mathrm{Ca}^{2+}$ promoted neither mitochondrial swelling (data not shown) nor $\mathrm{Ca} / \mathrm{Ba}$ accumulation (Fig. $3 B, C$ ). This substitution did not eliminate the redistribution of intracellular $\mathrm{Na}^{+}$and $\mathrm{K}^{+}$that normally follows NMDA stimulation (Fig. 3B,C). Together, these observations demonstrate that mitochondrial swelling depends on Ca overload. Paradoxically, the presence of FCCP during NMDA stimulation did not abolish mitochondrial swelling, although mitochondrial $\mathrm{Ca}^{2+}$ uptake and cytochrome $c$ release (see below) were strongly impaired. The ineffectiveness of FCCP-induced swelling may reflect mechanistic differences. For example, it is known that in a high- $\mathrm{Na}^{+}$medium de-energized mitochondria swell osmotically because of activation of a $\mathrm{Na}^{+} / \mathrm{H}^{+}$-exchanger and the accumulation of $\mathrm{Na}^{+}$together with a permeant counterion (Bernardi, 1999).

\section{Variable mitochondrial $\mathrm{Ca}^{2+}$ uptake underlies delayed cell death}

To this point, concentration data has been presented as averages of multiple mitochondria across multiple cells. This presentation is satisfactory for cells at rest, as well as after recovery, when $[\mathrm{Ca}]_{\text {mito }}$ is low and frequency distributions show that measurements are normally distributed (Fig. 4A). During the acute stimulus phase, however, when $[\mathrm{Ca}]_{\text {mito }}$ is, on average, very high, the distribution of individual measurements is strikingly broad and irregular (Fig. 4A); evidently, globally averaged concentrations mask this underlying variability.

The basis for the heterogeneous distribution of mitochondrial Ca resides, in large part, in the putative mechanism of mitochondrial $\mathrm{Ca}$ sequestration. A recent development in mitochondrial physiology is a renewed appreciation for the significance of calcium phosphate complex formation within the mitochondrial matrix. Such complexes, known for over 40 years (Carafoli, 2003), form when matrix total Ca exceeds $\sim 10-15 \mathrm{mmol} / \mathrm{kg}$. They are known to occur in isolated brain mitochondria exposed to high $\mathrm{Ca}^{2+}$ (Kristian et al., 2002; Chalmers and Nicholls, 2003) and have been characterized as inclusions of variable size within the mitochondria of physiologically stimulated neurons (Pivovarova et al., 1999, 2002). Here, we find that similar mitochondrial inclusions form during NMDA-stimulated $\mathrm{Ca}^{2+}$ entry (Fig. $4 B$ ). The punctate nature of these inclusions, together with their random distribution, leads to the irregular frequency distribution of individual measurements obtained with randomly placed probes that is seen after periods of strong Ca sequestration (Fig. $4 \mathrm{~A}$ ). Although the functional consequences of inclusion formation are not completely understood, it is evident that, in princi$\mathrm{pal}$, this process can serve as a robust $\mathrm{Ca}^{2+}$ buffering mechanism. Immobilization of $\mathrm{Ca}^{2+}$ as a readily resoluble, phosphorus-rich complex provides a chemistry-based mechanism that uses the solubility product of the complex to regulate mitochondrial free matrix $\mathrm{Ca}^{2+}$ so as to maintain this critical parameter at a fixed, relatively low level over a wide range of total accumulated Ca (Chalmers and Nicholls, 2003). A corollary consequence of this mechanism is that the appearance of complexes (as visible or otherwise detectable inclusions) does not necessarily connote damage, even though it is clear that mitochondria, because they always carry excessive Ca loads, will contain such inclusions. Indeed, the distinction between physiological (reversible) and pathological (irreversible) inclusion formation may be mainly quantitative. For example, injured mitochondria might be marked by more and larger inclusions, but this can be a subtle distinction, as illustrated by the inclusion-rich, but structurally 
Table 1. Elemental concentrations (millimoles per kilogram of dry weight) in the cytoplasm and mitochondria of cultured hippocampal neurons after excitotoxic stimulation with NMDA

\begin{tabular}{|c|c|c|c|c|c|c|c|}
\hline & $\begin{array}{l}\text { Number of } \\
\text { regions } \\
\text { analyzed }\end{array}$ & $\mathrm{Na}$ & $\mathrm{Mg}$ & $\mathrm{Cl}$ & $P$ & K & $\mathrm{Ca}$ \\
\hline \multicolumn{8}{|l|}{ Cytoplasm } \\
\hline NMDA & 70 & $768 \pm 28^{*}$ & $31 \pm 4^{*}$ & $491 \pm 17^{*}$ & $412 \pm 21^{*}$ & $64 \pm 7^{*}$ & $30 \pm 2^{*}$ \\
\hline NMDA plus MK-801 & 34 & $16 \pm 3^{* *}$ & $50 \pm 3^{* *}$ & $37 \pm 3^{* *}$ & $582 \pm 28^{* *}$ & $585 \pm 19^{* *}$ & $1.9 \pm 0.9^{* *}$ \\
\hline NMDA plus FCCP & 32 & $1156 \pm 82^{* *}$ & $46 \pm 5^{* *}$ & $675 \pm 57$ & $500 \pm 22$ & $66 \pm 5$ & $40 \pm 4^{* *}$ \\
\hline Recovered cells & 31 & $37 \pm 5$ & $52 \pm 4$ & $39 \pm 4$ & $533 \pm 26$ & $615 \pm 32$ & $3.1 \pm 1.7$ \\
\hline Degenerating cells ${ }^{a}$ & 21 & 1243 & 17 & 818 & 175 & 69 & 42 \\
\hline \multicolumn{8}{|l|}{ Mitochondria } \\
\hline Control & 46 & $15 \pm 3$ & $32 \pm 2$ & $20 \pm 3$ & $406 \pm 11$ & $369 \pm 11$ & $-0.1 \pm 0.7^{b}$ \\
\hline NMDA & 140 & $217 \pm 9^{*}$ & $41 \pm 2$ & $149 \pm 6^{*}$ & $609 \pm 29^{*}$ & $96 \pm 5^{*}$ & $529 \pm 50^{*}$ \\
\hline NMDA plus MK-801 & 33 & $7 \pm 3^{* *}$ & $27 \pm 2$ & $24 \pm 4^{* *}$ & $371 \pm 14^{* *}$ & $323 \pm 14^{* *}$ & $0.6 \pm 0.7^{* *}$ \\
\hline Degenerating cells ${ }^{a}$ & 26 & 285 & 19 & 184 & 395 & 14 & 402 \\
\hline
\end{tabular}

Data are given as means \pm SEM. The number of neurons analyzed was $15-20$ per experimental condition taken from three to four platings. Cultures were plunge-frozen immediately after a 20 min NMDA exposure and 2 and $6 \mathrm{hr}$ after stimulus. At $2 \mathrm{hr}$ after stimulus, Na-rich dead cells ( $<20 \%$ of all cells) were excluded. "Recovered cells" at $6 \mathrm{hr}$ after stimulus refers to cells with normal morphology and Na/ $\mathrm{K}$ ratios; "degenerating cells" indicates cells with compromised morphology (see Fig. 2) and poor $\mathrm{Na} / \mathrm{K}$ ratios.

${ }^{a}$ Given the extreme variability of these measurements, statistical errors are not meaningful and were not calculated.

${ }^{b}$ Below detection limit; negative value arises from statistical fluctuations.

***Different from control $(*)$ or from NMDA stimulation $(* *), p<0.05$, by ANOVA with post hoc Bonferroni test for multiple comparisons. Data for Ca in mitochondria after stimulation were not normally distributed (Kolmogorov-Smirnov test). Therefore, they were evaluated using nonparametric tests: Kruskal-Wallis rank ANOVA with post hoc Dunn's test for unbalanced data to compare with control or by Mann-Whitney $U$ test to compare with NMDA stimulation.

normal, mitochondria in Fig. $4 B$; based solely on the presence of inclusions, it would be difficult to predict whether or not these mitochondria had been injured.

An important finding is that the irregular distribution of individual $[\mathrm{Ca}]_{\text {mito }}$ measurements during acute NMDA stimulation is observed not only across multiple cells but also at the level of individual mitochondria within a single cell, as illustrated by the frequency distribution of $[\mathrm{Ca}]_{\text {mito }}$ measurements from a representative single cell (Fig. $4 C$ ). This observation indicates that heterogeneous mitochondrial Ca sequestration, whether physiological or pathophysiological, arises at the level of individual mitochondria and therefore leads to the following hypothesis. If the Ca load of an individual mitochondrion within a given neuron does not exceed available $\mathrm{Ca}^{2+}$ buffering capacity, this organelle will be only transiently affected and capable of full recovery. In contrast, Ca loads that overwhelm buffering capacity will lead to an uncontrolled rise in intramitochondrial free $\mathrm{Ca}^{2+}$, which in turn will trigger an injury response, e.g., a permeability transition and the release of apoptogenic proteins. If enough mitochondria exceed the damage threshold, the cumulative result would be an effective death signal. In this view, vulnerable neurons would be those that contain a critical fraction of mitochondria, the calcium load of which exceeds the damage threshold. Viewed another way, the hypothesis predicts that cells with high average $[\mathrm{Ca}]_{\text {mito }}$ would be expected to be the most vulnerable, because these are more likely to contain the requisite number of damaged organelles. The principle is illustrated in Figure $4 D$, a plot of mitochondria-to-mitochondria variability in eight different stimulated cells, in which cells B, C, and D would be predicted to be marked for delayed cell death. Certain predictions of this hypothesis can be tested. For example, injurious levels of sequestered $\mathrm{Ca}$ should be reflected in elevated matrix $\mathrm{Ca}$ (i.e., $\mathrm{Ca}$ not concentrated and sequestered in discrete, solid-phase inclusions) and should be associated with structural evidence of mitochondrial damage such as swelling and membrane rupture.

The variability of mitochondrial swelling within an NMDAstimulated neuron can, as noted previously, be readily seen in electron micrographs of directly frozen, cryosectioned neurons (Fig. 2); in micrographs of high-pressure frozen, freezesubstituted cells (Fig. 5A); and in those from chemically fixed preparations (Fig. 5B). Cells in all three types of preparations contained a mix of damaged and normal mitochondria, with a population of severely swollen mitochondria (Fig. $5 B$ ) scattered among structurally normal ones. Severely swollen mitochondria exhibit a loss of matrix density, disruption of cristae, and outer membrane rupture (Fig. $5 C$ ). The majority of mitochondria, swollen and non-swollen, contained Ca-rich inclusions (Fig. 5A). (In conventionally fixed, plastic-embedded preparations (Fig. $5 B, C)$, inclusions are not present because they had been extracted during tissue processing.) EPMA has resolution sufficient to measure mitochondrial Ca within and exclusive of the inclusions; the latter measure is defined as "matrix $[\mathrm{Ca}]_{\text {mito }}$." EPMA measurements on the inclusions themselves revealed that their Ca content was always very high and not significantly different between swollen and non-swollen mitochondria (1361 \pm 151 and $1234 \pm 121 \mathrm{mmol} / \mathrm{kg}$ dry weight, respectively). However, swollen mitochondria had, as predicted, higher matrix $[\mathrm{Ca}]_{\text {mito }}$ $(321 \pm 43 \mathrm{mmol} / \mathrm{kg}$, on average, vs $58 \pm 9 \mathrm{mmol} / \mathrm{kg})$, even while concentrations of other diffusible elements, e.g., $\mathrm{Na}$ and $\mathrm{K}$, were similar (Fig. 5D). The correlation between matrix $[\mathrm{Ca}]_{\text {mito }}$ elevation, swelling, and membrane rupture is further evidence to support the view that mitochondrial damage is a result of calcium overload.

Structurally damaged mitochondria with ruptured outer membranes, like those shown in Figure $5 C$, are the probable source for release of apoptogenic proteins such as cytochrome $c$. 
To address this possibility at the level of individual mitochondria, we used electron microscopic immunocytochemistry to characterize the NMDA-induced redistribution of cytochrome $c$. The results confirm that cytochrome $c$ is exclusively localized to mitochondria in prestimulus neurons (Fig. 6A). Shortly after termination of an NMDA stimulus, however, this protein was diffusely distributed in the cytoplasm but also retained in structurally intact mitochondria and, to some degree, in damaged mitochondria (Fig. 6B). Thus, cytochrome $c$ release was only partial, so that even in cells presumed to be targeted for delayed death, there were many structurally normal mitochondria that had retained cytochrome $c$. Moreover, quantitation of immunolabel particle density argues against significant release from intact mitochondria. Particle density in the cytoplasm of prestimulus neurons was $9 \pm$ 2 particles per unit area compared with $27 \pm 6(p<0.02) 30 \mathrm{~min}$ after stimulus removal. In contrast, there was no significant difference in immunoreactivity between mitochondria of prestimulus neurons and undamaged mitochondria of NMDA-stimulated neurons (120 \pm 15 vs $106 \pm 22$ particles per unit area, respectively).

Co-application of FCCP, which decreases $\mathrm{Ca}$ accumulation and improves survival (Fig. 3), prevented cytochrome $c$ release but not mitochondrial swelling (Fig. 6D), indicating that both mitochondrial $\mathrm{Ca}$ overload and swelling, but not swelling alone, are essential for cytochrome $c$ release under our conditions. Degenerating neurons at $6 \mathrm{hr}$ after stimulation still retained cytochrome $c$ in their mitochondria, which were, however, fewer in number (Fig. 6C). Taken together, these observations indicate that during and shortly after NMDA stimulation, cytochrome $c$ is released mainly, if not exclusively, from mitochondria damaged by calcium overload.

\section{Is MPT involved in cytochrome $c$ release?}

Certain observations bear on whether MPT is involved in delayed neuronal death under our conditions of stimulation. Both mitochondrial swelling and outer membrane rupture are thought to be typical indicators of MPT (Bernardi et al., 1994), while Ca loads comparable with those found here induce MPT in isolated brain mitochondria (Chalmers and Nicholls, 2003). However, the pore-forming process is usually defined as MPT if it is inhibited by CsA, and we have not observed a significant effect of CsA (in the concentration range $100 \mathrm{nM}$ to $20 \mu \mathrm{M}$ ) on $\Delta \Psi_{\mathrm{m}}$ depolarization or on neuronal viability (our unpublished observations). CsA is not an effective inhibitor of MPT at larger Ca loads (Brustovetsky and Dubinsky, 2000), which may well explain CsA insensitivity under our conditions, in which the calcium load in certain mitochondria exceeds $2.0 \mu \mathrm{mol} / \mathrm{mg}$ protein (Fig. $4 A$ ). In contrast, BA, an inhibitor of the adenine nucleotide translocator (ANT) that is a putative component of the NMDA treatment.
B

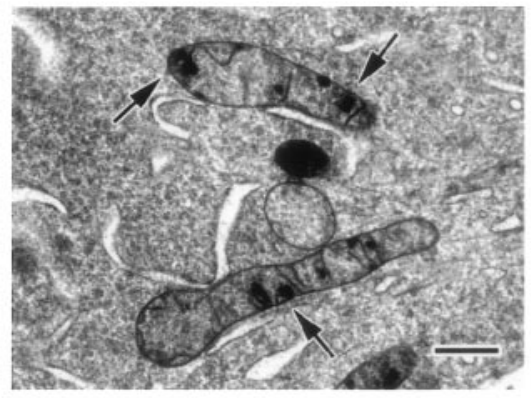

D

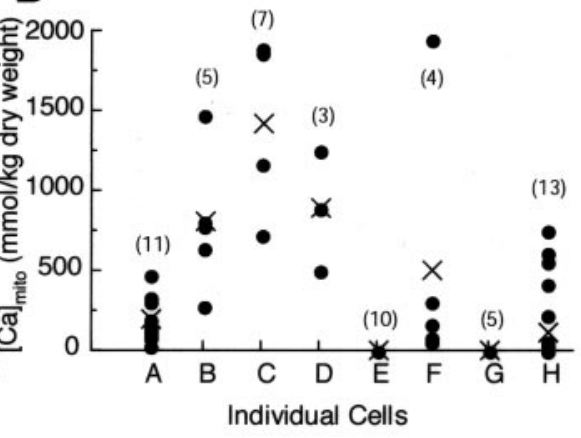

13)

Figure 4. NMDA stimulation induces localized and highly variable Ca accumulation in individual mitochondria. $A$, Frequency distributions of individual measurements of total Ca concentrations ([Ca $]_{\text {mito }}$ ) recorded from randomly selected mitochondria in multiple cells. Prestimulus frequency distribution is normal and narrow, consistent with the low basal [Ca $]_{\text {mito }}$ in all mitochondria NMDA-stimulated cells, illustrating wide cell-to-cell variability; the cross indicates cell averaged $[\mathrm{Ca}]_{\text {mito. }}$. The numbers in parentheses indicate the number of individual mitochondria analyzed. In all panels, cultures were rapidly frozen immediately after

MPT complex, significantly improved neuronal viability ( $\sim 25 \%$; our unpublished observations). This could be taken as evidence for MPT, although recent studies suggest that ANT may not be an essential component of the permeability pore complex (Kokoszka et al., 2004). Observation of CsAinsensitive, but BA-sensitive, calcium-induced MPT accompanied by cytochrome $c$ release parallels a recent study on isolated brain mitochondria in which the authors favored an MPT-dependent mechanism (Chinopoulos et al., 2003).

Given the circumstantial nature of available evidence, alternative mechanisms for cytochrome $c$ release must be considered. For example, a recent study describes a volume-dependent mechanism that does not require MPT but rather involves mitochondrial swelling attributable to $\mathrm{Ca}^{2+}$-induced $\mathrm{K}^{+}$uptake (Gogvadze et al., 2004). We conclude that the present results, $\mathrm{Ca}$ overload in a subpopulation of mitochondria accompanied by structural damage leading to cytochrome $c$ release, are consistent with an MPT-dependent mechanism, but other mechanisms cannot be ruled out.

\section{Discussion}

Despite significant progress in understanding the role of mitochondria in excitotoxic cell death, the precise nature of the mitochondrial defect, as well as the sequence of events downstream from mitochondrial damage, are not well understood. This study 

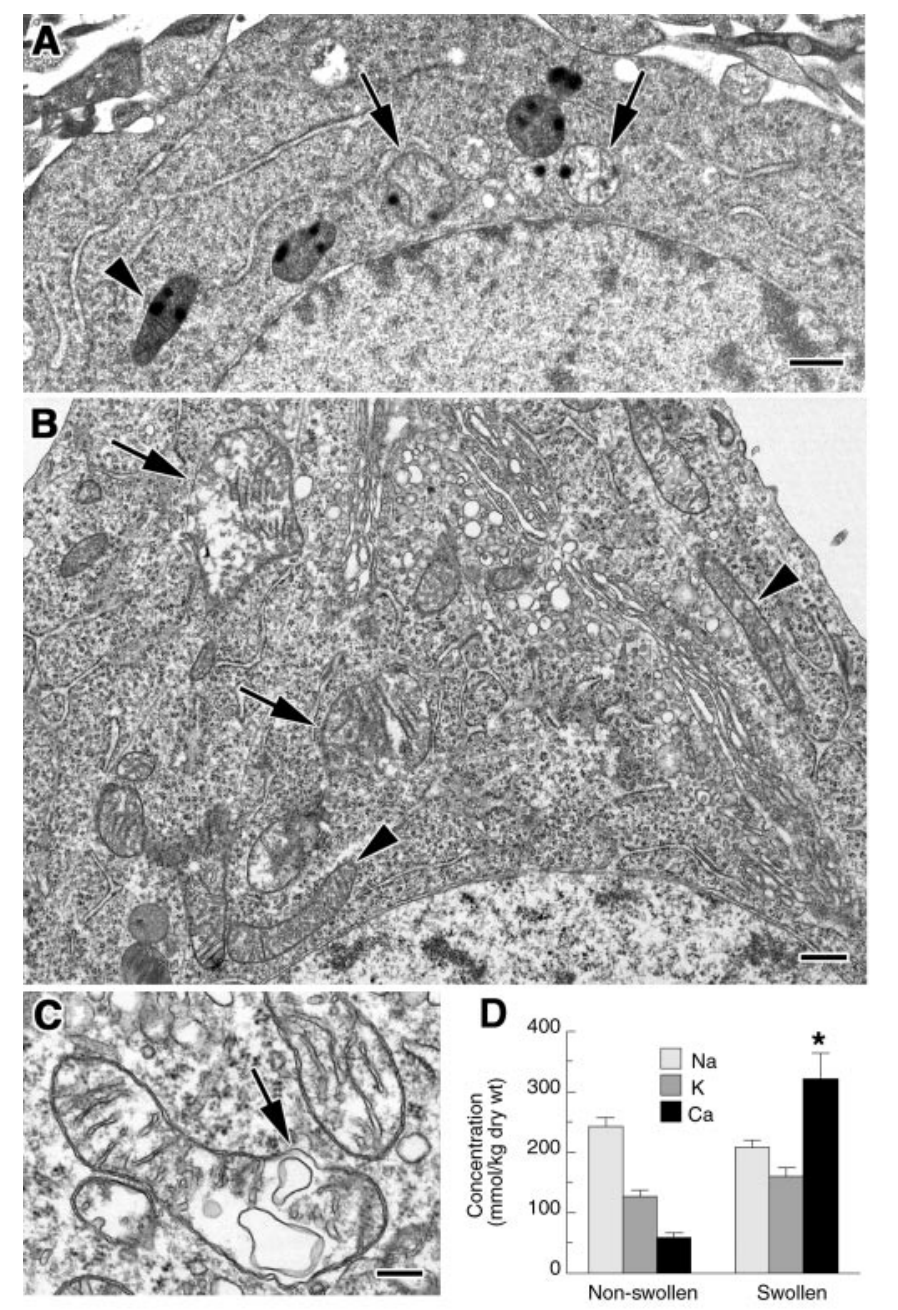

Figure 5. Excessive mitochondrial Ca accumulation leads to structural damage. $A, B$, Electron microscopy of NMDA-stimulated neurons fixed immediately after termination of the NMDA exposure reveals the presence of both damaged, swollen mitochondria with electron-lucent matrices (arrows) and structurally normal mitochondria (arrowheads). In A, high-pressure frozen, freeze-substituted preparation Ca-rich inclusions are seen in both normal and swollen mitochondria, but in $B$, conventionally fixed, plastic-embedded preparation mitochondrial inclusions are not present because they had been extracted during tissue processing. Scale bars, $500 \mathrm{~nm}$. C, Representative severely swollen mitochondrion exhibits loss of matrix density, distorted cristae, and outer membrane rupture (arrow). Shown is a conventionally fixed, plasticembedded preparation. Scale bar, $200 \mathrm{~nm}$. D, In swollen mitochondria, Ca concentrations in the inclusion-free matrix ( $321 \pm 43 \mathrm{mmol} / \mathrm{kg} ; n=43)$, but not the concentrations of $\mathrm{Na}$ and $\mathrm{K}$, are significantly higher ( $t$ test; $p<0.0001$ ) than in structurally normal mitochondria (58 \pm 9 $\mathrm{mmol} / \mathrm{kg} ; n=31$ ). This result is consistent with the hypothesis that mitochondrial swelling follows from Ca overload.

provides direct experimental evidence that overstimulation of NMDA receptors in cultured hippocampal neurons results in delayed cell death that is sequentially preceded by mitochondrial calcium overload, swelling, outer membrane rupture, and release of the apoptogenic protein(s). This pathway, however, occurs only in a subset of mitochondria; the remainder acutely accumulate calcium, swell, and depolarize, but these steps are reversible, so that the majority of mitochondria retain intermembrane proteins and recover normal functions after stimulus removal. This sequence, analogous to "limited MPT" (Crompton, 2000), creates conditions that are favorable for initiating and sustaining apoptotic pathways.
Excessive mitochondrial calcium loads induces structural damage and cytochrome $c$ release

NMDA overstimulation induces several mitochondrial structural changes. Swelling, which is variable from one mitochondrion to another, is clearly seen in both light and electron micrographs. Because the ultrastructural details are similar in directly frozen and chemically fixed preparations, it is unlikely that the observed NMDA-induced changes are fixation artifacts. At the light microscopy level, reversibly altered mitochondrial morphology, from rod-like to round, has also been reported for glutamate-stimulated forebrain neurons (Rintoul et al., 2003) and is thought to reflect mitochondrial fragmentation. Fragmentation is a feature of many forms of apoptosis (Karbowski and Youle, 2003) and cannot be ruled out in our cells, although here it would occur in addition to swelling.

Mitochondrial swelling is highly variable within individual neurons and depends on mitochondrial Ca accumulation. Swelling did not occur in zero $\mathrm{Ca}^{2+}$ medium or after substitution of extracellular $\mathrm{Ca}^{2+}$ by $\mathrm{Ba}^{2+}$, a result consistent with previous reports (Dubinsky and Levi, 1998). More importantly, swelling was correlated with a high level of matrix total Ca (i.e., Ca not associated with the inclusions described in Results). Because elevated matrix $\mathrm{Ca}$ is presumably an indicator of elevations in free mitochondrial $\mathrm{Ca}^{2+}$, an additional correlation between mitochondrial Ca overload, buffering failure, and swelling can be inferred. NMDA-dependent changes in free mitochondrial $\mathrm{Ca}^{2+}$ have recently been reported for cultured striatal neurons (Alano et al., 2002); these changes are linked to MPT in a subpopulation of mitochondria.

Severely swollen mitochondria often display ruptured outer membranes, implying that intermembrane apoptogenic proteins have been released from these mitochondria. Swelling and outer membrane rupture, features frequently observed in isolated mitochondria during $\mathrm{Ca}^{2+}$-dependent cytochrome $c$ release (Petit et al., 1998; Andreyev and Fiskum, 1999; Gogvadze et al., 2001; Brustovetsky et al., 2002), are known consequences of MPT. Moreover, Ca loads comparable with those found here induce MPT in isolated brain mitochondria (Chalmers and Nicholls, 2003). Our results (Fig. 5; Table 1) indicate that mitochondrial Ca remains high in swollen mitochondria after putative MPT. $\mathrm{Ca}^{2+}$ equilibration with the extramitochondrial space is expected after MPT, but this may occur slowly because injured mitochondria start with large Ca loads, particularly in the form of precipitates, and because elevated extramitochondrial $\mathrm{Ca}^{2+}$ reduces the driving force for $\mathrm{Ca}^{2+}$ efflux. Under these conditions, high mitochondrial Ca might be maintained for some time despite an open pore. Considered as a whole, available information suggests, but by no means proves, that in hippocampal neurons NMDA-induced cytochrome $c$ release occurs by an MPTdependent mechanism, although other mechanisms are certainly plausible.

Cytochrome $c$ is normally localized within mitochondria. The observation that it becomes distributed throughout the cytoplasm at the same time after NMDA stimulation that swollen, broken mitochondria appear implies that cytochrome $c$ was released from damaged mitochondria and not from the numerous intact mitochondria. In addition, it is clear that damaged mitochondria do not release cytochrome $c$ completely. These results are consistent with reported partial cytochrome $c$ release from several other neuronal preparations, including isolated brain mitochondria (Andreyev and Fiskum, 1999), cerebellar granule neurons (Atlante et al., 1999), hippocampal neurons (Lankiewicz et al., 2000), and cortical neurons (Brustovetsky et al., 2002). 
They contrast with the complete, synchronous release of cytochrome $c$ from all mitochondria during apoptosis in cytochrome c-GFP-transfected HeLa cells (Goldstein et al., 2000). Beyond differences in cell type, this discrepancy may reflect different mechanisms of membrane permeabilization (e.g., $\mathrm{Ca}^{2+}$-induced, MPT-dependent permeabilization during excitotoxic stimulation vs permeabilization by proteins of the Bcl-2 family during UV- or staurosporine-induced apoptosis).

\section{Size of the mitochondrial calcium load may determine neuronal vulnerability} NMDA stimulation when $\Delta \Psi_{\mathrm{m}}$ is depolarized (by FCCP) reduced mitochondrial $\mathrm{Ca}$ accumulation $\sim 70 \%$ compared with uptake when mitochondria were fully functional. It also reduced the death rate by $\sim 75 \%$, thus indicating that neuronal survival depends on mitochondrial $\mathrm{Ca}$ accumulation. Notwithstanding its crucial role in excitotoxic cell death, mitochondrial $\mathrm{Ca}^{2+}$ uptake is also a general and important feature of physiological signaling (Babcock and Hille, 1998; Friel, 2000). Thus, the question arises as to how much is too much: What concentration of intramitochondrial $\mathrm{Ca}$, in what location or chemical form, is toxic to mitochondria? Studies using fluorescent indicators have demonstrated large elevations of mitochondrial free $\mathrm{Ca}^{2+}$ after excitotoxic stimulation (Peng et al., 1998; Alano et al., 2002), although other studies show that with milder stimuli the concentration does not generally exceed a ceiling of 1-5 $\mu \mathrm{M}$ (David, 1999; Chalmers and Nicholls, 2003). The relatively constant level of free matrix $\mathrm{Ca}^{2+}$ over a wide range of $\mathrm{Ca}$ loads is consistent with chemical buffering that obeys the laws of mass action and suggests that a determining factor in the transition from physiological regulation to dysfunction may be an excessive amount of mitochondrial $\mathrm{Ca}$. Indeed, quantitative measurements of $\mathrm{Ca}^{2+}$ releasable from mitochondria after glutamatestimulated loading indicate that millimolar concentrations of $\mathrm{Ca}^{2+}$ had been sequestered (Brocard et al., 2001). In the present study, direct measurements of total $\mathrm{Ca}$ in individual mitochondria show that mitochondria of NMDA-overstimulated hippocampal neurons accumulate extremely large amounts of Ca. This concentration is much higher than found for mitochondria of physiologically stimulated (Pivovarova et al., 1999, 2002) or even injured (Taylor et al., 1999) neurons but comparable with the Ca loads known to induce the release of cytochrome $c$ and apoptosis-inducing factor in isolated mitochondria (Petit et al., 1998; Andreyev and Fiskum, 1999; Chalmers and Nicholls, 2003).

Despite generally extremely high average $[\mathrm{Ca}]_{\text {mito }}$, only about half of the neurons that survive the acute phase of insult will later undergo delayed death, raising the question of why some neurons are more vulnerable than others. One explanation may lie in the variability of $\mathrm{Ca}$ accumulation at the level of individual mitochondria, as illustrated in Figure 4, such that vulnerability is dictated by a critical fraction of mitochondria exceeding a threshold $[\mathrm{Ca}]_{\text {mito }}$ level. The reason(s) for extreme variability of mitochondrial $\mathrm{Ca}^{2+}$ uptake is unknown but may reflect mitochondrial
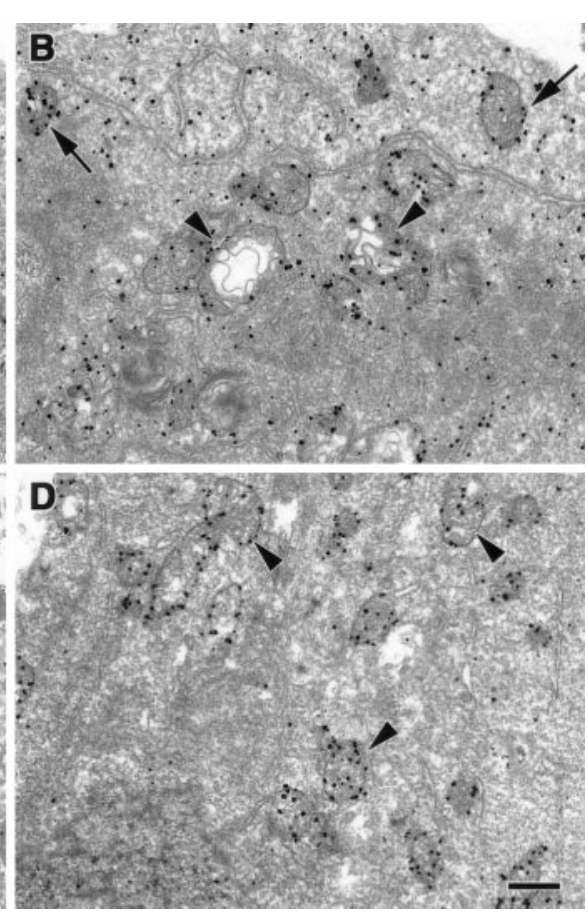

Figure 6. NMDA stimulation leads to cytochrome c release from a subpopulation of mitochondria. Shown is ultrastructural usively localized within mitochondria, mainly at the periphery (arrows). $B$ Thirty minutes after a 20 min NMDA exposure, arrowheads). C, In a degenerating neuron at $6 \mathrm{hr}$ after stimulation, cytochrome c was still retained in the few remaining min before NMDA exposure did not abolish mitochondrial swelling (arrowheads) at 30 min after stimulation but did prevent Scale bar (for all panels), $500 \mathrm{~nm}$

location or local $\left[\mathrm{Ca}^{2+}\right]_{\mathrm{i}}$ fluctuations (Rizzuto et al., 2000). Alternatively, $[\mathrm{Ca}]_{\text {mito }}$ heterogeneity between individual mitochondria could plausibly reflect fluctuations in $\Delta \Psi_{\mathrm{m}}$ (Buckman and Reynolds, 2001; Collins et al., 2002) or the availability of inorganic phosphate (Kristian et al., 2001; Chalmers and Nicholls, 2003).

Although the evidence for mitochondrial Ca overload is compelling, the mechanism linking this to apoptogen release remains obscure. In our cells, coapplication of NMDA and FCCP led to a decrease in mitochondrial Ca accumulation and prevented cytochrome $c$ release but did not abolish mitochondrial swelling. Therefore, both high mitochondrial $\mathrm{Ca}$ and swelling, but not swelling alone, appear to be necessary for cytochrome $c$ release. Because swelling per se is insufficient, an additional role for mitochondrial calcium beyond that of inducing swelling is implied. One possibility may be to promote the dissociation of cytochrome $c$ from cardiolipin, a step critical for cytochrome $c$ release (Ott et al., 2002; Crompton, 2003).

\section{What is the mechanism of cell death?}

By $2 \mathrm{hr}$ after stimulus removal, neurons that had not died by acute necrosis had mainly recovered their prestimulus structure and composition, with the majority of mitochondria regaining volume regulation, prestimulus levels of $[\mathrm{Ca}]_{\text {mito }}, \Delta \Psi_{\mathrm{m}}$, and normal function. If pro-apoptotic cells are present at this time, at least some of their mitochondria must be capable of producing ATP to activate downstream energy-dependent apoptotic processes. The activation of caspase- 3 is energy dependent and a well recognized indicator for the onset of apoptosis. However, only a small fraction of our cells express active caspase-3 after NMDA 
stimulation (our unpublished observations). Nonetheless, the initiation of apoptosis is still possible because in hippocampal neurons, late activation of the $\mathrm{Ca}^{2+}$-dependent neutral protease calpain I inhibits caspase-dependent apoptotic pathways (Lankiewicz et al., 2000). Although the involvement of calpain under our conditions remains to be established, a late, secondary $\mathrm{Ca}^{2+}$ elevation in the cytoplasm of recovered neurons correlates with cell viability (our unpublished data) and could conceivably promote calpain activation. Alternatively, caspase-independent pathways may be involved (Cregan et al., 2002; Yu et al., 2002). Clearly, several important details need to be worked out, among them the effects of cross talk between caspase and calpain pathways, as well as any role for reactive oxygen species or Bcl-2 family proteins. The relevance of these questions to disease and injury insures that they will remain topics of active investigation.

\section{References}

Alano CC, Beutner G, Dirksen RT, Gross RA, Sheu SS (2002) Mitochondrial permeability transition and calcium dynamics in striatal neurons upon intense NMDA receptor activation. J Neurochem 80:531-538.

Andreyev A, Fiskum G (1999) Calcium induced release of mitochondrial cytochrome c by different mechanisms selective for brain versus liver. Cell Death Differ 6:825-832.

Ankarcrona M, Dypbukt JM, Bonfoco E, Zhivotovsky B, Orrenius S, Lipton SA, Nicotera P (1995) Glutamate-induced neuronal death: a succession of necrosis or apoptosis depending on mitochondrial function. Neuron 15:961-973.

Atlante A, Gagliardi S, Marra E, Calissano P, Passarella S (1999) Glutamate neurotoxicity in rat cerebellar granule cells involves cytochrome $\mathrm{c}$ release from mitochondria and mitochondrial shuttle impairment. J Neurochem 73:237-246.

Babcock DF, Hille B (1998) Mitochondrial oversight of cellular $\mathrm{Ca}^{2+}$ signaling. Curr Opin Neurobiol 8:398-404.

Bernardi P (1999) Mitochondrial transport of cations: channels, exchangers, and permeability transition. Physiol Rev 79:1127-1155.

Bernardi P, Broekemeier KM, Pfeiffer DR (1994) Recent progress on regulation of the mitochondrial permeability transition pore; a cyclosporinsensitive pore in the inner mitochondrial membrane. J Bioenerg Biomembr 26:509-517.

Bernardi P, Petronilli V, Di Lisa F, Forte M (2001) A mitochondrial perspective on cell death. Trends Biochem Sci 26:112-117.

Bonfoco E, Krainc D, Ankarcrona M, Nicotera P, Lipton SA (1995) Apoptosis and necrosis: two distinct events induced, respectively, by mild and intense insults with $\mathrm{N}$-methyl-D-aspartate or nitric oxide/superoxide in cortical cell cultures. Proc Natl Acad Sci USA 92:7162-7166.

Brocard JB, Tassetto M, Reynolds IJ (2001) Quantitative evaluation of mitochondrial calcium content in rat cortical neurones following a glutamate stimulus. J Physiol (Lond) 531:793-805.

Brustovetsky N, Dubinsky JM (2000) Limitations of cyclosporin A inhibition of the permeability transition in CNS mitochondria. J Neurosci 20:8229-8237.

Brustovetsky N, Brustovetsky T, Jemmerson R, Dubinsky JM (2002) Calcium-induced cytochrome $\mathrm{c}$ release from CNS mitochondria is associated with the permeability transition and rupture of the outer membrane. J Neurochem 80:207-218.

Buchanan RA, Leapman RD, O’Connell MF, Reese TS, Andrews SB (1993) Quantitative scanning transmission electron microscopy of ultrathin cryosections: subcellular organelles in rapidly frozen liver and cerebellar cortex. J Struct Biol 110:244-255.

Buckman JF, Reynolds IJ (2001) Spontaneous changes in mitochondrial membrane potential in cultured neurons. J Neurosci 21:5054-5065.

Budd SL, Nicholls DG (1996) Mitochondria, calcium regulation, and acute glutamate excitotoxicity in cultured cerebellar granule cells. J Neurochem 67:2282-2291.

Budd SL, Tenneti L, Lishnak T, Lipton SA (2000) Mitochondrial and extramitochondrial apoptotic signaling pathways in cerebrocortical neurons. Proc Natl Acad Sci USA 97:6161-6166.

Carafoli E (2003) Historical review: mitochondria and calcium: ups and downs of an unusual relationship. Trends Biochem Sci 28:175-181.

Chalmers S, Nicholls DG (2003) The relationship between free and total calcium concentrations in the matrix of liver and brain mitochondria. J Biol Chem 278:19062-19070.

Chinopoulos C, Starkov AA, Fiskum G (2003) Cyclosporin A-insensitive permeability transition in brain mitochondria: inhibition by 2-aminoethoxydiphenyl borate. J Biol Chem 278:27382-27389.

Choi DW (1987) Ionic dependence of glutamate neurotoxicity. J Neurosci 7:369-379.

Collins TJ, Berridge MJ, Lipp P, Bootman MD (2002) Mitochondria are morphologically and functionally heterogeneous within cells. EMBO J $21: 1616-1627$

Cregan SP, Fortin A, MacLaurin JG, Callaghan SM, Cecconi F, Yu SW, Dawson TM, Dawson VL, Park DS, Kroemer G, Slack RS (2002) Apoptosis-inducing factor is involved in the regulation of caspaseindependent neuronal cell death. J Cell Biol 158:507-517.

Crompton M (2000) Mitochondrial intermembrane junctional complexes and their role in cell death. J Physiol (Lond) 529:11-21.

Crompton M (2003) On the involvement of mitochondrial intermembrane junctional complexes in apoptosis. Curr Med Chem 10:1473-1484.

David G (1999) Mitochondrial clearance of cytosolic $\mathrm{Ca}^{2+}$ in stimulated lizard motor nerve terminals proceeds without progressive elevation of mitochondrial matrix $\left[\mathrm{Ca}^{2+}\right.$. J Neurosci 19:7495-7506.

Dubinsky JM (1993) Intracellular calcium levels during the period of delayed excitotoxicity. J Neurosci 13:623-631.

Dubinsky JM, Levi Y (1998) Calcium-induced activation of the mitochondrial permeability transition in hippocampal neurons. J Neurosci Res 53:728-741.

Duchen MR (2000) Mitochondria and $\mathrm{Ca}^{2+}$ in cell physiology and pathophysiology. Cell Calcium 28:339-348.

Friberg H, Wieloch T (2002) Mitochondrial permeability transition in acute neurodegeneration. Biochimie 84:241-250.

Friel DD (2000) Mitochondria as regulators of stimulus-evoked calcium signals in neurons. Cell Calcium 28:307-316.

Gillessen T, Budd SL, Lipton SA (2002) Excitatory amino acid neurotoxicity. Adv Exp Med Biol 513:3-40.

Gogvadze V, Robertson JD, Zhivotovsky B, Orrenius S (2001) Cytochrome c release occurs via $\mathrm{Ca}^{2+}$-dependent and $\mathrm{Ca}^{2+}$-independent mechanisms that are regulated by Bax. J Biol Chem 276:19066-19071.

Gogvadze V, Robertson JD, Enoksson M, Zhivotovsky B, Orrenius S (2004) Mitochondrial cytochrome $\mathrm{c}$ release may occur by volume-dependent mechanisms not involving permeability transition. Biochem J 378:213-217.

Goldstein JC, Waterhouse NJ, Juin P, Evan GI, Green DR (2000) The coordinate release of cytochrome $\mathrm{c}$ during apoptosis is rapid, complete and kinetically invariant. Nat Cell Biol 2:156-162.

Hall TA, Gupta BL (1983) The localization and assay of chemical elements by microprobe methods. Q Rev Biophys 16:279-339.

Karbowski M, Youle RJ (2003) Dynamics of mitochondrial morphology in healthy cells and during apoptosis. Cell Death Differ 10:870-880.

Khodorov B, Pinelis V, Vergun O, Storozhevykh T, Vinskaya N (1996) Mitochondrial deenergization underlies neuronal calcium overload following a prolonged glutamate challenge. FEBS Lett 397:230-234.

Kiedrowski L, Brooker G, Costa E, Wroblewski JT (1994) Glutamate impairs neuronal calcium extrusion while reducing sodium gradient. Neuron 12:295-300.

Kokoszka JE, Waymire KG, Levy SE, Sligh JE, Cai J, Jones DP, MacGregor GR, Wallace DC (2004) The ADP/ATP translocator is not essential for the mitochondrial permeability transition pore. Nature 427:461-465.

Kristian T, Bernardi P, Siesjo BK (2001) Acidosis promotes the permeability transition in energized mitochondria: implications for reperfusion injury. J Neurotrauma 18:1059-1074.

Kristian T, Weatherby TM, Bates TE, Fiskum G (2002) Heterogeneity of the calcium-induced permeability transition in isolated non-synaptic brain mitochondria. J Neurochem 83:1297-1308.

Kroemer G, Reed JC (2000) Mitochondrial control of cell death. Nat Med 6:513-519.

Lankiewicz S, Luetjens CM, Bui NT, Krohn AJ, Poppe M, Cole GM, Saido TC, Prehn JH (2000) Activation of calpain I converts excitotoxic neuron death into a caspase-independent cell death. J Biol Chem 275:17064-17071.

Lemasters JJ, Qian T, He L, Kim JS, Elmore SP, Cascio WE, Brenner DA (2002) Role of mitochondrial inner membrane permeabilization in necrotic cell death, apoptosis, and autophagy. Antioxid Redox Signal 4:769-781. 
Lu ZM, McLaren RS, Winters CA, Ralston E (1998) Ribosome association contributes to restricting mRNAs to the cell body of hippocampal neurons. Mol Cell Neurosci 12:363-375.

Luetjens CM, Bui NT, Sengpiel B, Munstermann G, Poppe M, Krohn AJ, Bauerbach E, Krieglstein J, Prehn JH (2000) Delayed mitochondrial dysfunction in excitotoxic neuron death: cytochrome $\mathrm{c}$ release and a secondary increase in superoxide production. J Neurosci 20:5715-5723.

Mattson MP, Kroemer G (2003) Mitochondria in cell death: novel targets for neuroprotection and cardioprotection. Trends Mol Med 9:196-205.

Mattson MP, Zhang Y, Bose S (1993) Growth factors prevent mitochondrial dysfunction, loss of calcium homeostasis, and cell injury, but not ATP depletion in hippocampal neurons deprived of glucose. Exp Neurol 121:1-13.

Mayer ML, Vyklicky Jr L, Westbrook GL (1989) Modulation of excitatory amino acid receptors by group IIIB metal cations in cultured mouse hippocampal neurones. J Physiol (Lond) 415:320-350.

Murphy AN, Fiskum G, Beal MF (1999) Mitochondria in neurodegeneration: bioenergetic function in cell life and death. J Cereb Blood Flow Metab 19:231-245.

Nicholls DG, Budd SL (2000) Mitochondria and neuronal survival. Physiol Rev 80:315-360.

Orrenius S, Zhivotovsky B, Nicotera P (2003) Regulation of cell death: the calcium-apoptosis link. Nat Rev Mol Cell Biol 4:552-565.

Ott M, Robertson JD, Gogvadze V, Zhivotovsky B, Orrenius S (2002) Cytochrome c release from mitochondria proceeds by a two-step process. Proc Natl Acad Sci USA 99:1259-1263.

Peng TI, Jou MJ, Sheu SS, Greenamyre JT (1998) Visualization of NMDA receptor-induced mitochondrial calcium accumulation in striatal neurons. Exp Neurol 149:1-12.

Petit PX, Goubern M, Diolez P, Susin SA, Zamzami N, Kroemer G (1998) Disruption of the outer mitochondrial membrane as a result of large amplitude swelling: the impact of irreversible permeability transition. FEBS Lett 426:111-116.

Pivovarova NB, Hongpaisan J, Andrews SB, Friel DD (1999) Depolarization-induced mitochondrial Ca accumulation in sympathetic neurons: spatial and temporal characteristics. J Neurosci 19:6372-6384.

Pivovarova NB, Pozzo-Miller LD, Hongpaisan J, Andrews SB (2002) Correlated calcium uptake and release by mitochondria and endoplasmic reticulum of CA3 hippocampal dendrites after afferent synaptic stimulation. J Neurosci 22:10653-10661.

Pozzo-Miller LD, Pivovarova NB, Leapman RD, Buchanan RA, Reese TS, Andrews SB (1997) Activity-dependent calcium sequestration in dendrites of hippocampal neurons in brain slices. J Neurosci 17:8729-8738.
Reynolds IJ (1999) Mitochondrial membrane potential and the permeability transition in excitotoxicity. Ann NY Acad Sci 893:33-41.

Richter K (1994) A cryoglue to mount vitreous biological specimens for cryoultramicrotomy at 110K. J Microsc 173:143-147.

Rintoul GL, Filiano AJ, Brocard JB, Kress GJ, Reynolds IJ (2003) Glutamate decreases mitochondrial size and movement in primary forebrain neurons. J Neurosci 23:7881-7888.

Rizzuto R, Bernardi P, Pozzan T (2000) Mitochondria as all-round players of the calcium game. J Physiol (Lond) 529:37-47.

Schinder AF, Olson EC, Spitzer NC, Montal M (1996) Mitochondrial dysfunction is a primary event in glutamate neurotoxicity. J Neurosci 16:6125-6133

Shuman H, Somlyo AV, Somlyo AP (1976) Quantitative electron probe microanalysis of biological thin sections: methods and validity. Ultramicroscopy 1:317-339.

Stout AK, Raphael HM, Kanterewicz BI, Klann E, Reynolds IJ (1998) Glutamate-induced neuron death requires mitochondrial calcium uptake. Nat Neurosci 1:366-373.

Tanner VA, Ploug T, Tao-Cheng JH (1996) Subcellular localization of SV2 and other secretory vesicle components in PC12 cells by an efficien method of preembedding EM immunocytochemistry for cell cultures. J Histochem Cytochem 44:1481-1488.

Taylor CP, Weber ML, Gaughan CL, Lehning EJ, LoPachin RM (1999) Oxygen/glucose deprivation in hippocampal slices: altered intraneuronal elemental composition predicts structural and functional damage. J Neurosci 19:619-629.

Vergun O, Keelan J, Khodorov BI, Duchen MR (1999) Glutamate-induced mitochondrial depolarisation and perturbation of calcium homeostasis in cultured rat hippocampal neurones. J Physiol (Lond) 519:451-466.

Wang GJ, Thayer SA (1996) Sequestration of glutamate-induced $\mathrm{Ca}^{2+}$ loads by mitochondria in cultured rat hippocampal neurons. J Neurophysiol 76:1611-1621.

White RJ, Reynolds IJ (1995) Mitochondria and $\mathrm{Na}^{+} / \mathrm{Ca}^{2+}$ exchange buffer glutamate-induced calcium loads in cultured cortical neurons J Neurosci 15:1318-1328.

Yu SW, Wang H, Poitras MF, Coombs C, Bowers WJ, Federoff HJ, Poirier GG, Dawson TM, Dawson VL (2002) Mediation of poly(ADP-ribose) polymerase-1-dependent cell death by apoptosis-inducing factor. Science 297:259-263.

Zeng YS, Xu ZC (2000) Co-existence of necrosis and apoptosis in rat hippocampus following transient forebrain ischemia. Neurosci Res 37:113125 . 